\title{
DESENVOLVIMENTO DE UM PROJETO PARA UMA TAMPA DE BACIA SANITÁRIA COM ACIONAMENTO POR PEDAL
}

Marcos Fernando da Silva Rehling Junior (marcosrelhingjr@ hotmail.com) - Universidade Federal de Pelotas, (UFPel).

Dener Schwanz (denerschwanz@gmail.com) - Universidade Federal de Pelotas, (UFPel).

Matheus Kohls (mkohls2610@gmail.com) - Universidade Federal de Pelotas, (UFPel).

Ariel Ferreira Bartz (arielfrbartz@gmail.com) - Universidade Federal de Pelotas, (UFPel).

Aline Soares Pereira (professora.alinesp@gmail.com) - Universidade Federal de Pelotas, (UFPel).

\section{RESUMO}

As empresas estão cada vez mais reconhecendo que a saída para se manter no mercado e crescer constantemente, está no contínuo desenvolvimento de produtos novos e aprimorados. O Processo de Desenvolvimento de Produtos (PDP) deve ser visto como uma questão estratégica dentro das organizações, já que este permite maiores chances de sucesso no lançamento de novos produtos e agrega valor aos negócios. Nesse sentido, o presente trabalho objetivou desenvolver o projeto de um dispositivo para levantar a tampa de bacia sanitária com acionamento por pedal. Através do levantamento das principais metodologias de PDP selecionou-se o modelo de Rozenfeld et al. (2006), que compreende três macrofases sendo subdivididas em nove fases. Dentre as principais questões realizadas ao longo da aplicação do modelo ficam evidenciadas a pesquisa por patentes, a análise do ciclo de vida do produto, definição do processo de fabricação e seu fluxograma, definição da ergonomia, análise de viabilidade econômica, bem como a aplicação do FMEA e o desenho do produto através do SolidWorks. Como resultado da aplicação do modelo, obteve-se o projeto para o produto proposto que se mostrou conveniente por atingir o objetivo proposto.

Palavras-chave: inovação; modelos de PDP; gestão de produtos; projeto de produto. 


\section{INTRODUÇÃO}

A competitividade empresarial é uma das características do mundo globalizado, com isso, o bom desempenho das organizações é vital para que as mesmas consigam se manter vivas no mercado. Logo, aplicar métodos adequados para desenvolver seus produtos e processos é de suma importância, pois garantem uma chance muito maior de sucesso para as empresas. Os métodos de desenvolvimento de produtos estabelecem ferramentas para atender a um mercado que busca a inovação constantemente. O Instituto Brasileiro de Geografia e Estatística (IBGE), através da sua Pesquisa de Inovação - PINTEC, a qual traz indicadores de inovação sobre as empresas industriais brasileiras, dos setores de eletricidade e gás e de serviços selecionados, de um total de 132.529 empresas analisadas no Brasil, 47.693 implementaram inovações de produto ou processo na pesquisa realizada em 2014, o que demonstra que apenas $35,99 \%$ das empresas foram inovadoras (IBGE, 2016). De acordo com a consultoria McKinsey \& Company (2020), grande parte das empresas entendem a importância da inovação para o crescimento das mesmas, porém poucas a executam na prática. Acredita-se que os executivos muitas vezes não tem clareza sobre os problemas e como melhorá-los. Dados apontam que $84 \%$ dos executivos entendem que a inovação é importante para o crescimento, porém apenas $6 \%$ deles acreditam que sua performance nesse quesito seja satisfatória, logo desenvolver produtos inovadores de maneira correta é essencial.

Nesse sentido, o artigo apresenta o projeto de um dispositivo para levantar a tampa de bacia sanitária com acionamento por pedal. Este produto promove uma higiene mais adequada no manuseio das tampas, já que não é necessário utilizar as mãos, permite uma posição ergonômica melhor para os seus usuários e garante a praticidade pelo seu sistema de acionamento. Destaca-se ainda que, atualmente, há uma demanda por soluções imediatas que auxiliem na mitigação da expansão do vírus da Covid-19, ainda, percebe-se que no Brasil não dispomos deste tipo de proposta sendo comercializada, possuímos apenas tampas de bacias sanitárias comuns, logo é um produto que vem para atender uma demanda de mercado real.

\section{REVISÃO TEÓRICA}

\subsection{Inovação}

Como já foi bem enfatizado na introdução, não podemos falar em PDP dissociado à inovação, tendo em vista que é fator essencial nesse ramo de negócios. Para a Organização para Cooperação e Desenvolvimento Econômico (OCDE), a inovação pode ser entendida como 
"um produto ou processo novo ou melhorado (ou uma combinação dos mesmos) que difere significativamente dos produtos ou processos anteriores” (OSLO manual, 2018, p. 20).

Silva et al. (2018) citam a inovação como uma ótima ferramenta para o aumento da competitividade, onde nos dias atuais frente ao mundo globalizado se faz como um processo obrigatório para o sucesso. Os autores ainda comentam o fato que muitos acabam se equivocando, a dúvida entre inovação e invenção, ambas as palavras muitas vezes são entendidas como se fossem a mesma coisa, porém são bem diferentes.

Para Slack et al. (2018), a invenção trata-se da criação de algo novo, mas esse novo produto ou método não necessariamente será algo realmente prático, com capacidade de gerar valor econômico e de ser vendido para a sociedade. A inovação por sua vez, além de trazer o caráter de novidade, traz consigo o processo capaz de transformar as ideias em algo que consiga gerar retorno seja para a empresa que desenvolve, ou seja, para seus clientes.

Por fim, a importante questão do design, elemento essencial para uma boa dose de inovação, segundo Bürdek (2010) ele é em si um processo criativo, o design não acontece por acaso, é resultado de um processo de desenvolvimento atrelado a diversas decisões e condições impostas. Para o autor, ele é ligado a fatores socioeconômicos, culturais, tecnológicos, bem como fundamentos históricos e condições da produção, fatores ergonômicos e ecológicos.

\subsection{O processo de desenvolvimento de produtos}

Para Rozenfeld et al. (2006), o desenvolvimento de novos produtos vem através de uma série de atividades, onde estas são realizadas de acordo com a necessidade do mercado, da tecnologia disponível e seguindo estratégias competitivas e de produto da empresa, para que por meio dessas atividades se possa chegar ao projeto do produto e de seu processo de fabricação. Os autores também destacam que é papel importante do desenvolvimento do produto fazer um acompanhamento do produto após seu lançamento, isso possibilita futuras mudanças das especificações que podem ser necessárias ou até mesmo a descontinuidade do produto no mercado, com isso é possível uma melhor organização das lições aprendidas em todo ciclo de vida do produto.

$\mathrm{O}$ ato de desenvolver um produto está relacionado ao sentido de propiciar ao mercado o que ele precisa, e isso acontece "a partir de estudos detalhados e de modelagens", para então fornecer um produto ou serviço conforme seus clientes desejam, através da manufatura ou da oferta do serviço (GHELEN, 2018, p. 12). Nesse sentido, o mesmo autor relata que para a 
criação e lançamento de um produto o mesmo deve ser gerado através de um processo multidisciplinar, ou seja, todos os setores da organização devem estar envolvidos no seu desenvolvimento, assim propiciando um produto com o menor custo e eficácia possível.

Slack et al. (2018) citam que o projeto pode agregar muito valor as organizações, melhorando muito o desempenho das mesmas, onde com uma boa prática de projeto pode-se ter um produto ou serviço diferenciado, onde são mais atraentes para o cliente e também ajudam a tornar os lançamentos de produtos mais bem sucedidos.

\subsection{Modelos de PDP}

Nem todo modelo de PDP é perfeitamente adequado para todo tipo de organização, ainda segundo Bonsiepe (1978) ${ }^{l}$ apud Jung et al. (2009), os modelos devem funcionar de maneira a auxiliar no processo. Devem ser escolhidos pela equipe responsável pela engenharia de produto o modelo mais indicado dado o porte da organização e onde ele será aplicado.

Codinhoto (2003) apresenta alguns autores que trazem modelos mais amplos de PDP e ainda atenta para o fato de que a maioria dos autores mostrados por ele na Figura 1 trata o PDP como um processo de negócios, enquanto o modelo de Pahl e Beitz (1996) trata apenas como um processo de projeto.

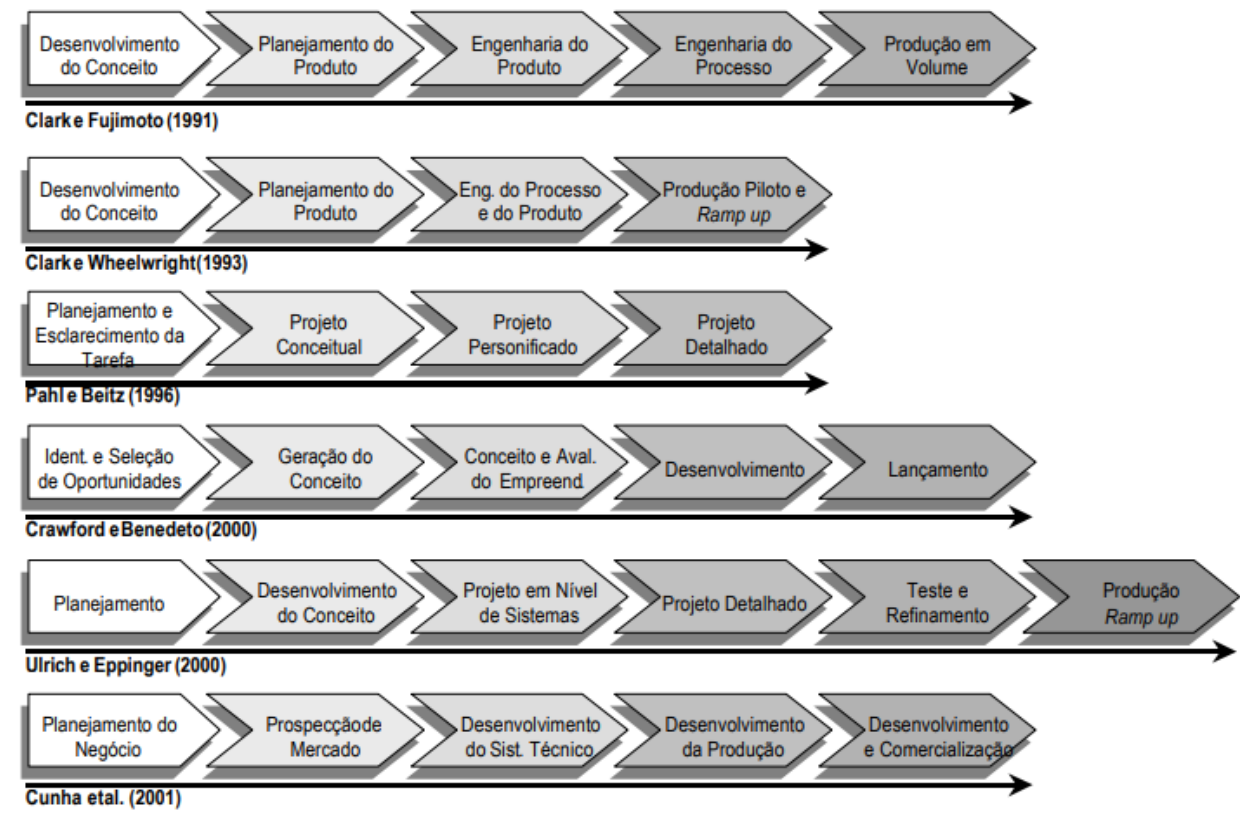

FIGURA 1 - Divisão do PDP em fases segundo alguns autores pesquisados. Fonte: Codinhoto (2003)

\footnotetext{
${ }^{1}$ BONSIEPE, G. Teoria y práctica del deseño industrial. Barcelona: Gustavo Gili, 1978.
} 
Segundo Codinhoto (2003), percebe-se que as delimitações e os limites entre cada fase não são completamente definidos e não ficam perfeitamente visíveis. Nota-se também que a divisão das fases não é totalmente igual, elas variam bastante.

Neves et al. (2011) chamam atenção para um modelo que não foi incluído nas análises dos autores anteriores, o Modelo para a Gestão e o Desenvolvimento de Produtos de Rozenfeld et al. (2006). De acordo com os autores esse modelo possui um maior detalhamento nas suas operações, com um bom sequenciamento de atividades que possibilita tornar o processo dinâmico. Somado a isso, ele apresenta uma ótima adaptação a diversos tipos de projetos, onde pode sofrer pequenas alterações em algumas etapas sem prejudicar o processo como um todo.

De acordo com Rozenfeld et al. (2006), o modelo empregado na gestão do PDP tem influência direta no desempenho do processo, ainda ressalta que um bom modelo deve ser capaz de atingir ótimos resultados, com o mínimo de recursos possíveis, sejam eles tempo ou custos.

\section{METODOLOGIA}

Neste trecho apresenta-se os métodos utilizados que forneceram suporte à pesquisa, elementos esses essenciais de cunho científico. O trabalho apresenta uma pesquisa exploratória, onde segundo Medeiros e Tomasi (2016), esse tipo de pesquisa envolve como objetivo uma maior familiaridade com o tema, além disso, se enquadra como qualitativa, onde ela "desenvolve-se numa situação natural, oferecendo riqueza de dados descritivos, bem como focalizando a realidade de forma complexa e contextualizada" (LAKATOS; MARCONI, 2017, p. 302).

A busca pela compreensão dos modelos de PDP se deu através de uma pesquisa bibliográfica, “a pesquisa bibliográfica é elaborada com base em material já publicado. Tradicionalmente, esta modalidade de pesquisa inclui material impresso, como livros, revistas, jornais, teses, dissertações e anais de eventos científicos" (GIL, 2017, p. 28). A busca por informações se deu de forma virtual por meio das bases de periódicos da Coordenação de Aperfeiçoamento de Pessoal de Nível Superior (CAPES) e biblioteca virtual da universidade. Para a realização desta etapa optou-se por palavras-chave como: processo de desenvolvimento de produto, pesquisa e desenvolvimento, inovação em produtos, gestão do produto, gestão da inovação, gestão de novos produtos, design, produtos inovadores, entre outras.

Posteriormente, fez-se um fichamento em todas as fontes de informações consultadas, onde as 
ideias principais e referências eram anotadas para que então, através do modelo preliminar de sumário de revisão bibliográfica, fosse sendo redigido o texto então apresentado de maneira estruturada.

\subsection{Escolha do modelo de PDP}

Através da leitura sobre as principais metodologias de PDP selecionou-se o modelo de Rozenfeld et al. (2006) por ser mais completo em termos de gestão de produto e além disso, por tratar o processo de maneira detalhada ao longo de todo ciclo de vida do produto, desde o acompanhamento da produção, até a descontinuidade do produto no mercado.

\subsection{Modelo de Rozenfeld et al. (2006)}

Rozenfeld et al. (2006) explicam que seu modelo é dividido em três macrofases, sendo elas subdivididas em fases e atividades. As macrofases do modelo são: Pré-Desenvolvimento, Desenvolvimento e Pós-Desenvolvimento. As macrofases são subdivididas em nove fases, sendo que cada fase é determinada de acordo com a entrega de um conjunto de resultados, assim ao final de cada fase elas são verificadas e avaliadas, os chamados gates. Nos gates é feita uma análise a respeito da qualidade dos resultados da fase e a discussão de possíveis problemas encontrados. Dentre algumas fases podem-se destacar as de projeto informacional, projeto conceitual e projeto detalhado, onde apresentam ferramentas que serão aplicadas no trabalho, como análise paramétrica, sistemas CAD, FMEA, pesquisa de mercado, entre outras. Para a pesquisa de mercado, visando a obtenção das informações pertinentes ao público-alvo, realizou-se uma pesquisa através de um questionário via Google Forms. O questionário apresenta 16 perguntas que foram aplicadas aos alunos do Centro de Engenharias (CEng). De acordo com o site do CEng, baseado no Portal Institucional da UFPel, o ambiente possui um total de 1825 alunos matriculados em cursos de graduação e pós-graduação. Assim calculouse o tamanho da amostra necessária para aplicar a pesquisa. Para a população de alunos, considerando um grau de confiança de $95 \%$ e uma margem de erro de $8 \%$, o tamanho da amostra necessária seria de 139 respostas, entretanto o questionário obteve um total de 143 respostas.

\section{RESULTADOS E DISCUSSÃO}

A aplicação prática do modelo de PDP de Rozenfeld et al. (2006) ao produto pode ser vista na sequência. 


\subsection{Pré-Desenvolvimento}

\subsubsection{Planejamento estratégico dos produtos}

Segundo Rozenfeld et al. (2006), é nesta fase em especial que deve-se pensar em relação as estratégias de mercado utilizadas pela empresa, bem como as estratégias tecnológicas. Para o produto proposto neste artigo, encontrou-se algumas soluções para adequar essa questão de manipular a tampa do assento, entretanto, no mercado brasileiro não foi possível encontrar nada comercial. Sendo assim, como forma de fazer uma análise preliminar no mercado, foi realizada uma busca nas principais fontes de patentes, onde se cabem destacar duas das principais, a Tampa com acionador para vaso sanitário (MU 9102355-6 U2) do Instituto Nacional da Propriedade Industrial (INPI) e a Hands-free toilet seat lifiting device (Dispositivo de elevação de assento de vaso sanitário sem usar as mãos) (US 8,020,221 B2) do United States Patent and Trademark Office (USPTO). Ainda, deve-se estar atento para cumprir as normas inerentes ao produto, sendo que umas das principais a ser destacada aqui é a norma NBR 9050 de Acessibilidade a Edificações, Mobiliário, Espaços e Equipamentos Urbanos. A norma da Associação Brasileira de Normas Técnicas - ABNT NBR 9050, no tocante às bacias sanitárias, descreve que o produto deve ter uma altura máxima entre o chão e a parte superior do assento de 0,46 m para bacias de adulto e 0,36 m para bacias infantis, ou seja, a alavanca de contato que fará o levantamento dos assentos deve ter a menor espessura possível, a fim de não ultrapassar essas medidas estipuladas na para a bacia em si, levando em consideração a sua resistência mecânica (ABNT, 2020). Por fim, realizou-se uma pesquisa de mercado visando à obtenção das informações pertinentes ao público-alvo. A pesquisa aponta que 97,2\% dos entrevistados não consideram que os banheiros públicos sejam higiênicos, que 83,9\% acreditam ser anti-higiênico tocar na tampa da bacia sanitária para levantá-la e que $72 \%$ estariam dispostos a comprar o produto. Os resultados são demonstrados no Gráfico 1.

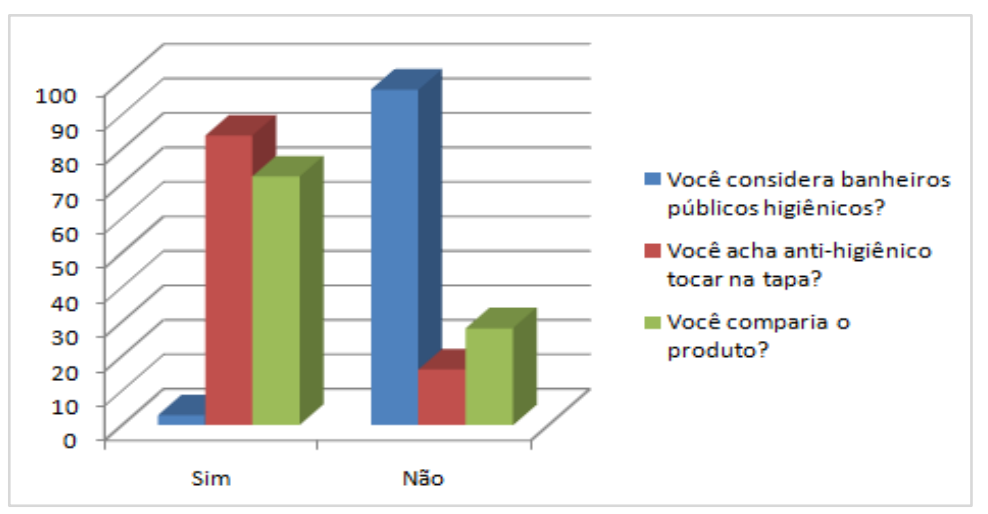

GRÁFICO 1 - Pesquisa de mercado. Fonte: Elaborado pelos autores. 


\subsection{Desenvolvimento}

\subsubsection{Projeto informacional}

O objetivo principal do projeto informacional baseia-se, segundo Rozenfeld et al. (2006) em desenvolver um conjunto de informações com a finalidade de resolver o problema ou concluir o projeto que a equipe está envolvida. Neste momento, que se faz uma síntese, de todas as informações levantadas sobre o problema com o objetivo de procurar entender ele da melhor forma possível e posteriormente ser transmitido para a sua solução ou neste caso, para o produto. De forma a definir os requisitos do produto realizou-se uma análise paramétrica demonstrada na Figura 2. Segundo Baxter (2011), a análise paramétrica serve para comparar os produtos em desenvolvimento com produtos existentes ou concorrentes, para isso se utiliza variáveis que podem ser medidas.

\begin{tabular}{|c|c|c|c|c|}
\hline Produto & & & & \\
\hline Nome & $\begin{array}{l}\text { Pedal para levantar } \\
\text { tampa de privada }\end{array}$ & Flipper & $\begin{array}{c}\text { ToiletSeat Lifting } \\
\text { Pedal }\end{array}$ & $\begin{array}{c}\text { Acionador de tampa de } \\
\text { bacia sanitária por } \\
\text { pedal (Projeto Artigo) }\end{array}$ \\
\hline Material & Plástico & Plástico & Plástico & Plástico \\
\hline Origem & Importado & Importado & Importado & Nacional \\
\hline Cores & Branca & Branca & Branca & Branca \\
\hline Preço & $\$ 24,99$ & $\$ 6,00$ & $\$ 28,73$ & $\mathrm{R} \$ 70,00$ \\
\hline Design & Bom & Bom & Regular & Ótimo \\
\hline Uso & Residencial & Residencial & Residencial & Residencial/Comercial \\
\hline $\begin{array}{c}\text { Locais } \\
\text { de } \\
\text { Vendas }\end{array}$ & $\begin{array}{l}\text { Mercado Exterior } \\
\text { (Brasil somente } \\
\text { importando) }\end{array}$ & $\begin{array}{c}\text { Mercado Exterior } \\
\text { (Brasil somente } \\
\text { importando) }\end{array}$ & $\begin{array}{c}\text { Mercado Exterior } \\
\text { (Brasil somente } \\
\text { importando) }\end{array}$ & $\begin{array}{l}\text { Lojas de materiais de } \\
\text { contrução e para casa }\end{array}$ \\
\hline
\end{tabular}

FIGURA 2 - Análise paramétrica do produto. Fonte: Rehling Junior et al. (2020)

Através da análise paramétrica ficam evidenciados que os principais benefícios do produto frente aos concorrentes são a possibilidade de compra facilitada no país e o preço, sendo um dos mais baratos entre os analisados.

A análise do ciclo de vida do produto considerou o levantamento dos requisitos dos clientes, análise paramétrica, além do projeto conceitual e detalhado, contendo diversas ferramentas aplicadas como a modelagem funcional do produto, matriz morfológica, definição da estrutura do produto, definição do processo produtivo e seu fluxograma, FMEA, entre diversas outras atividades. Nas etapas de introdução, crescimento e maturidade se fez um estudo sobre o mercado, mas de forma didática. Na etapa de declínio avaliou-se a possível oferta de produtos 
semelhantes, concorrentes e ações alternativas foram planejadas como o redesign. Outra possibilidade apontada foi a retirada do produto do mercado, o mesmo podendo ser reutilizado como fonte de matéria-prima reciclada. Além disso, parte da coleta desses resíduos é associada as reformas que podem ocorrer nos ambientes, onde muitas vezes pode ocorrer do produto ser descartado. Esse descarte deverá ser feito de maneira correta, de acordo com a coleta seletiva da cidade onde o usuário reside, sendo que algumas indicações estarão presentes na embalagem.

\subsubsection{Projeto conceitual}

Segundo Rozenfeld et al. (2006), nesta fase a equipe responsável pelo projeto visa a busca, criação, representação e seleção de soluções para o problema do projeto. A criação deve ser feita com um direcionamento para as necessidades e requisitos do produto. A representação pode ser feita em paralelo com a criação, por meio de esquemas ou manuais. Por fim, a seleção dessas soluções deve ser embasada em métodos que visam atender as necessidades do produto.

Para melhor compressão do produto, realizou-se uma análise funcional, onde fica estabelecida a função principal, secundárias e entre outras. A análise é feita através de um diagrama de relações hierárquicas que mostra um esquema de relações e interconexões em formato de uma árvore ao contrário, como demonstrado na Figura 3. 


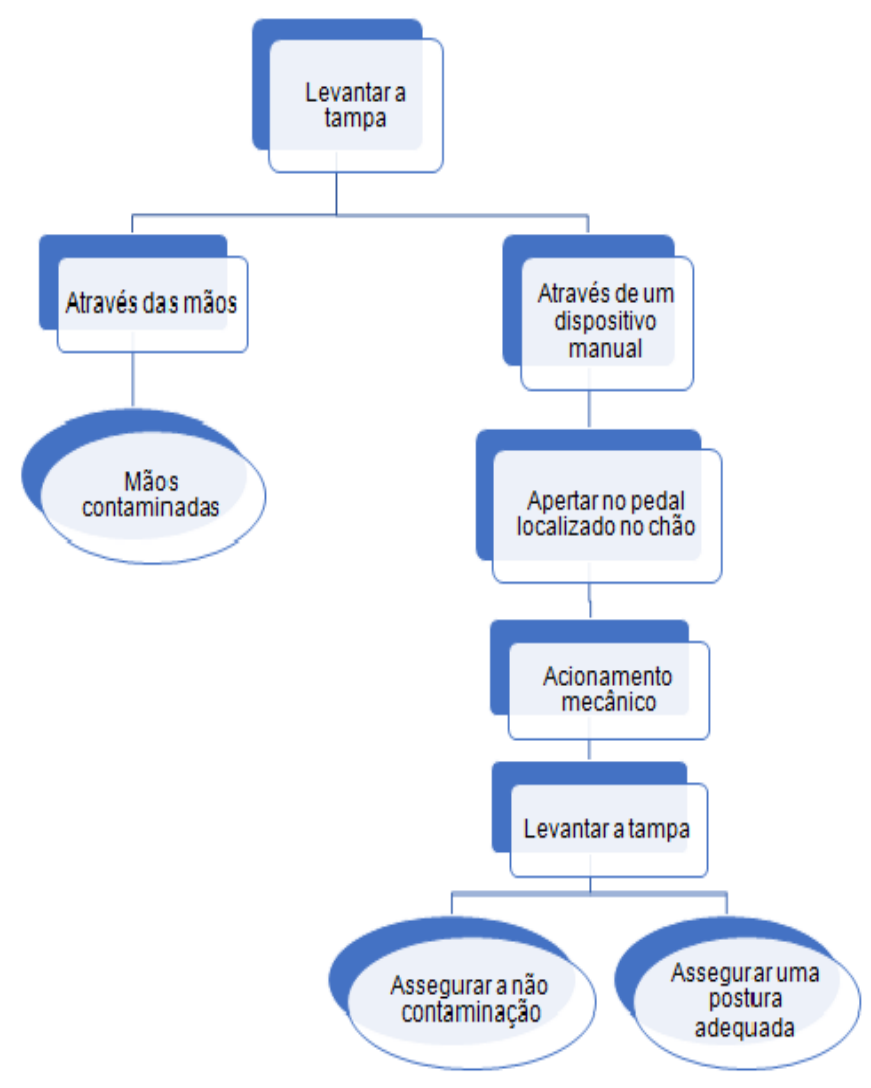

FIGURA 3 - Análise Funcional do produto proposto. Fonte: Rehling Junior et al. (2020)

De acordo com Rozenfeld et al. (2006), na definição da arquitetura do produto, o mesmo deve ser analisado pela sua composição em diversas partes, e elas são desdobradas em Sistemas, Subsistemas e Componentes (SSCs) que deverão atender as funções do produto.

A Figura 4 mostra uma imagem do produto e suas divisões em vários componentes de um todo, a Figura 5 mostra a relação desses componentes bem como seu material, que será o Polietileno de Alta Densidade (PEAD). Ambos mostram através de uma análise estrutural a arquitetura do produto. 


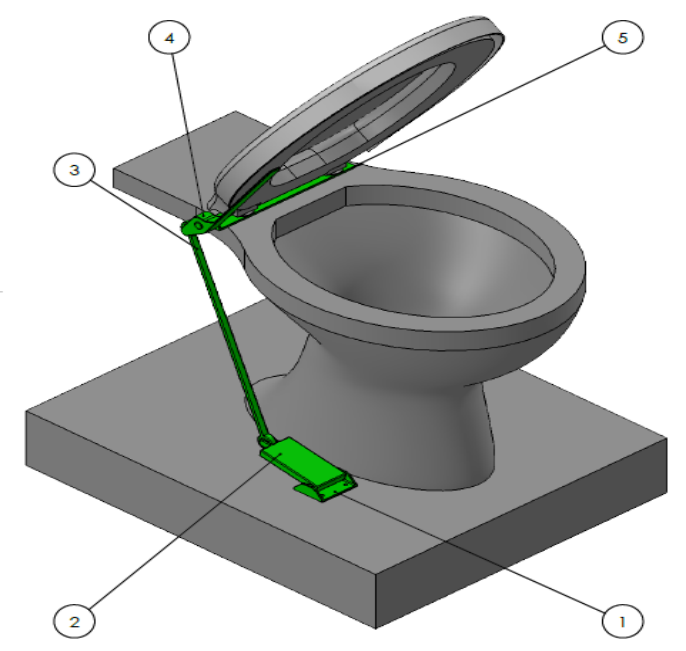

FIGURA 4 - Análise Estrutural. Fonte: Rehling Junior et al. (2020)

\begin{tabular}{|c|c|c|c|}
\hline $\mathbf{N}^{\mathbf{o}}$ & Componente & Quantidade & Material \\
\hline 1 & Base pedal & 1 & PEAD \\
\hline 2 & Pedal & 1 & PEAD \\
\hline 3 & Haste & 1 & PEAD \\
\hline 4 & Alavanca & 1 & PEAD \\
\hline 5 & Base alavanca & 1 & PEAD \\
\hline
\end{tabular}

FIGURA 5 - Relação de componentes e materiais. Fonte: Rehling Junior et al. (2020)

Considerando o aspecto ergonômico, o produto se apresenta muito eficaz, pode-se entender pelo fato de não haver a necessidade do usuário se curvar para fazer o levantamento da tampa da bacia sanitária. Pensando-se em pessoas saudáveis e com bons hábitos esse aspecto não seria tão importante como a questão da higiene, porém segundo a Pesquisa Nacional por Amostra de Domicilios (PNAD) do IBGE, publicada em 2010, levando em consideração as dores crônicas, as dores na coluna são a segunda condição mais presente no Brasil com $13,5 \%$, perdendo apenas para a hipertensão com $14 \%$.

\subsubsection{Projeto detalhado}

De acordo com Rozenfeld et al. (2006), nesta fase são elaborados projetos, o desenvolvimento e a finalização das especificações do produto.

Como maneira de buscar uma avaliação dos itens e documentos do produto utilizou-se o Failure Mode and Effect Analysis (FMEA) - Análise dos Modos de Falha e Efeitos. O FMEA visa a minimização ou eliminação de falhas críticas, onde para um novo produto, o método pode ser utilizado para o desenvolvimento de ações que busquem a minimização da 
ocorrência de potenciais falhas (CARPINETTI, 2016). A Figura 6 apresenta a análise do FMEA para o produto desenvolvido.

\begin{tabular}{|c|c|c|c|c|c|c|c|c|c|}
\hline \multicolumn{2}{|c|}{ FMEA } & \multicolumn{8}{|c|}{ Projeto de Produto } \\
\hline \multicolumn{2}{|c|}{ Cliente: interno } & \multicolumn{8}{|c|}{ Aplicação: Desenvolvimento de um novo produto } \\
\hline \multicolumn{2}{|c|}{ Data: $11 / 2020$} & \multicolumn{8}{|c|}{ Produto/Processo: tampa de bacia sanitária com acionamento por pedal } \\
\hline \multicolumn{2}{|c|}{ Fornecedor: } & \multicolumn{8}{|c|}{ Áreas envolvidas: Engenharia do Produto, Qualidade, Compras e Produção } \\
\hline \multirow{4}{*}{ Item } & \multirow{4}{*}{ Componente } & \multicolumn{3}{|c|}{ Data elaboração: 03/11/20 } & \multicolumn{5}{|c|}{ ATUAL } \\
\hline & & \multicolumn{3}{|c|}{ Falhas Possiveis } & \multicolumn{5}{|c|}{ ÍNDICES } \\
\hline & & & & & & 0 & $G$ & D & $\mathrm{R}$ \\
\hline & & MODO & EFEITO (S) & CAUSA (S) & CONTROLES & ocorrência & gravidade & detecção & risco \\
\hline \multirow{2}{*}{1} & \multirow{2}{*}{ Pedal } & \multirow{2}{*}{$\begin{array}{l}\text { Deformação } \\
\text { no encaixe } \\
\text { que conecta a } \\
\text { haste }\end{array}$} & \multirow{2}{*}{$\begin{array}{l}\text { Interrupção no } \\
\text { funcionamento }\end{array}$} & $\begin{array}{l}\text { Aplicação de } \\
\text { força em } \\
\text { excesso para } \\
\text { acionamento }\end{array}$ & $\begin{array}{l}\text { Ensaios } \\
\text { mecânicos }\end{array}$ & 3 & 7 & 3 & 63 \\
\hline & & & & \begin{tabular}{|l|} 
Matéria-prima \\
plástica macia
\end{tabular} & \begin{tabular}{|c|} 
Inspeção das \\
especificações \\
de matéria- \\
prima
\end{tabular} & 3 & 7 & 2 & 42 \\
\hline 2 & Haste & $\begin{array}{c}\text { Desgaste nas } \\
\text { conexões } \\
\text { móveis }\end{array}$ & $\begin{array}{l}\text { Instabilidade } \\
\text { do movimento }\end{array}$ & \begin{tabular}{|c|} 
Material não é \\
liso o \\
suficiente ou \\
com pouca \\
lubrificação \\
\end{tabular} & \begin{tabular}{|c|} 
Inspeção da \\
matéria-prima e \\
produto \\
acabado \\
\end{tabular} & 2 & 4 & 2 & 16 \\
\hline 3 & Alavanca & $\begin{array}{c}\text { Deformação } \\
\text { devido ao } \\
\text { peso do } \\
\text { assento } \\
\end{array}$ & $\begin{array}{l}\text { Levantamento } \\
\text { parcial da } \\
\text { tampa }\end{array}$ & $\begin{array}{l}\text { Tampa mais } \\
\text { pesada, fora } \\
\text { dos padrões }\end{array}$ & $\begin{array}{c}\text { Verificação do } \\
\text { peso das } \\
\text { tampas } \\
\text { comerciais } \\
\end{array}$ & 2 & 8 & 1 & 16 \\
\hline 4 & $\begin{array}{c}\text { Base } \\
\text { alavanca }\end{array}$ & $\begin{array}{l}\text { Desgaste na } \\
\text { conexão com } \\
\text { a alavanca }\end{array}$ & $\begin{array}{l}\text { Instabilidade } \\
\text { do movimento }\end{array}$ & \begin{tabular}{|c} 
Material não é \\
liso o \\
suficiente ou \\
com pouca \\
lubrificação
\end{tabular} & \begin{tabular}{|c|} 
Inspeção da \\
matéria-prima e \\
produto \\
acabado
\end{tabular} & 2 & 2 & 2 & 8 \\
\hline
\end{tabular}

FIGURA 6 - FMEA do produto. Fonte: Rehling Junior et al. (2020)

De acordo com a análise realizada no FMEA, percebe-se que a falha mais preocupante, que possivelmente poderá ocorrer depois de feito o produto seria a deformação plástica no pedal, ou seja, uma deformação entre o encaixe do pedal com a haste. Para ter uma ideia do dispositivo no uso diário, pretende-se realizar ensaios de fadiga para determinar o tempo de vida antes da possível falha. Outros ensaios também podem ser realizados no protótipo para buscar a melhoria do sistema. Além disso, será feita a inspeção da matéria-prima, sendo esta falha a ser atacada em um primeiro momento.

\subsection{Pós-Desenvolvimento}

Esta é a macrofase final do modelo, é onde foram tratadas as questões relativas ao acompanhamento do produto no pós lançamento. Para Rozenfeld et al. (2006) o principal objetivo dessa fase é de garantir o acompanhamento do desempenho do produto na produção e no mercado. Isso é realizado de forma a identificar as oportunidades de melhorias e visando, 
se necessário, a retirada do produto com o menor impacto possível, tanto para os consumidores, meio ambiente e empresa. Por fim a descontinuidade do produto será realizada de acordo com o que é definido no ciclo de vida do produto, ou seja, quando o produto não apresentar mais vantagens econômicas à empresa.

\section{CONCLUSÃO}

Fica evidente ao longo da leitura do trabalho a importância dos modelos de PDP no que tange a geração de valores para as empresas, isto não apenas em grandes empresas, mas em todas as organizações que desejam obter vantagens estratégicas, competitivas e estejam voltadas à um processo de inovação. Logo, a escolha de um modelo de PDP adequado a cada tipo de produto e organização é de suma importância para que se gere produtos com êxito e qualidade ao consumidor final. Com isso, através da análise sobre os principais modelos, constatou-se que o modelo de Rozenfeld et al. (2006) se mostrou o mais indicado para o produto proposto por se tratar de um dos modelos mais amplos e completos e também por abranger questões vinculadas a ergonomia e ao meio ambiente.

Dentre as principais questões realizadas ao longo da aplicação do modelo ficam evidenciadas a pesquisa por patentes, a análise do ciclo de vida do produto, definição do processo de fabricação e seu fluxograma, definição da ergonomia, análise de viabilidade econômica, bem como a aplicação do FMEA e o desenho do produto através do SolidWorks.

\section{REFERÊNCIAS}

ASSOSIAÇÃO BRASILEIRA DE NORMAS TÉCNICAS. NBR 9050: Acessibilidade a edificações, mobiliário, espaços e equipamentos urbanos. 4. ed. Rio de Janeiro, 2020.

BAXTER, M. Projeto de produto: guia prático para o design de novos produtos. 3. ed. São Paulo: Blucher, 2011.

BÜRDEK, B. E. Design: história, teoria e prática do design de produtos. 2. ed. São Paulo: Blucher, 2010.

CARPINETTI, L. C. R. Gestão da qualidade: conceitos e técnicas. 3. ed. São Paulo: Atlas, 2016.

CODINHOTO, R. Diretrizes para o planejamento e controle integrado dos processos de projeto e produção na construção civil. 2003. Dissertação (Mestrado em Engenharia) Programa de Pós-Graduação em Engenharia Civil, Universidade Federal do Rio Grande do Sul. Porto Alegre, 2003.

GHELEN, R. Z. C. Desenvolvimento de produtos. Porto Alegre: SER - SAGAH, 2018.

GIL, A. C. Como elaborar projetos de pesquisa. 6.ed. Rio de Janeiro: Atlas, 2017. 
INSTITUTO BRASILEIRO DE GEOGRAFIA E ESTATÍSTICA. Pesquisa de inovação PINTEC. Rio de Janeiro, $2016 . \quad$ Disponível em: https://www.ibge.gov.br/estatisticas/multidominio/9141-pesquisa-deinovacao.html?=\&t=destaques. Acesso em: 7 abr. 2020.

INSTITUTO BRASILEIRO DE GEOGRAFIA E ESTATÍSTICA. Pesquisa Nacional por Amostras de Domicílios - PNAD: um panorama da saúde no Brasil. Rio de Janeiro, 2010. Disponível em: https://biblioteca.ibge.gov.br/biblioteca-catalogo?id=244356\&view=detalhes. Acesso em: 14 out. 2020.

JUNG, C. F. et al. Análise estrutural e síntese das características lineares e sistêmicas de modelos de desenvolvimento de produto. Revista Liberato, Novo Hamburgo, v. 10, n. 13, p. 103-114, jan./jun. 2009.

LAKATOS, E. M; MARCONI, M. A. Metodologia científica. 7. ed. Rio de Janeiro: Atlas, 2017.

McKINSEY \& COMPANY. How we help clients. Disponível em: https://www.mckinsey.com/business-functions/strategy-and-corporate-finance/how-we-helpclients/growth-and-innovation\#. Acesso em: 7 abr. 2020.

MEDEIROS, J. B; TOMASI, C. Redação de artigos científicos. Rio de Janeiro: Atlas, 2016.

NEVES, E. B. et al. Abordagem metodológica do processo de desenvolvimento de produto (PDP) para o projeto de um dispositivo filetador para garrafas PET. ln: CONGRESSO BRASILEIRO DE GESTÃO DE DESENVOLVIMENTO DE PRODUTO, 8., Porto Alegre, 2011. Anais [...]. Porto Alegre: [s.n.], 2011.

OSLO manual 2018. guidelines for collecting, reporting and using data on innovation. 4. ed. Paris: OCDE, 2018.

ROZENFELD, H. et al. Gestão de desenvolvimento de produtos: uma referência para melhoria do processo. São Paulo: Saraiva, 2006.

SILVA, F. P. et al. Gestão da inovação. Porto Alegre: SAGAH, 2018.

SLACK, N. et al. Administração da produção. 8. ed. Rio de Janeiro: Atlas, 2018. 